\title{
Kidney Infection, CTCAE
}

National Cancer Institute

\section{Source}

National Cancer Institute. Kidney Infection, CTCAE. NCI Thesaurus. Code C143632.

A disorder characterized by an infectious process involving the kidney. 